\title{
Correction to: Science, ethics, responsibility and COVID-19
}

\author{
Péter Lőw ${ }^{1}$ (D)
}

Published online: 27 May 2021

(c) Akadémiai Kiadó Zrt. 2021

\section{Correction to: Biologia Futura \\ https://doi.org/10.1007/s42977-020-00057-x}

There was an error in the contents of the special issue as specified in the initial online publication. The original article has been corrected.

The original article can be found online at https://doi.org/10.1007/ s42977-020-00057-x.

$\square$ Péter Lőw

peter.low@ttk.elte.hu

1 Department of Anatomy, Cell and Developmental Biology, Eötvös University, Budapest, Hungary 